\title{
APLIKASI PENYIMPANAN FILE ALTERNATIF BAGI PENGGUNA SMARTPHONE BERBASIS ANDROID
}

\author{
Darwin*, Umar Gadjah, Egi Meilan Simarmata, Yonata Laia \\ Program Studi Sistem Informasi Fakultas Teknologi dan Ilmu Komputer Universitas Prima Indonesia \\ E-mail: *chaidarwin@gmail.com
}

\begin{abstract}
ABSTRAK - Perkembangan teknologi informasi dan komunikasi sudah sangat pesat, terutama teknologi cloud computing. Cloud computing merupakan teknologi masa kini yang sedang hangat dibicarakan oleh pakar teknologi informasi. Salah satu implementasi teknologi cloud computing adalah layanan penyimpanan file. Pada saat ini smartphone sudah menjadi barang yang umum digunakan publik. Smartphone adalah sebuah perangkat yang dapat diinstall berbagai aplikasi dan menggunakan sistem operasi android. Semua kegiatan yang direkam dan difoto oleh smartphone tersimpan pada memori smartphone sehingga mengurangi ruang memori pada smartphone serta memperlambat cara kerja sistem operasi pada smartphone tersebut. Hal ini sangat menganggu pengguna smartphone itu sendiri karena harus menghapus beberapa file penting dari ruang penyimpanan bahkan aplikasi lain, agar smartphone bisa bekerja secara normal dan efektif kembali. Aplikasi penyimpanan file alternatif bagi pengguna smartphone berbasis android ini adalah solusi yang tepat serta efektif untuk permasalahan penyimpanan file yang sering dialami pengguna smartphone.
\end{abstract}

Kata kunci : Penyimpanan File, Cloud Computing, Aplikasi.

\section{PENDAHULUAN}

Pada era perkembangan teknologi informasi dan komunikasi yang sudah sangat pesat, komputasi awan (cloud computing) sudah menjadi pembicaraan hangat dalam dunia teknologi informasi. Teknologi cloud computing dikembangkan supaya dapat mengakses sumber daya / resources dan aplikasi dari mana saja melalui internet.

Sudah banyak perusahaan besar seperti Google, Amazon, Microsoft dan lainnya yang telah menyediakan bermacam macam jenis layanan cloud computing agar dapat digunakan oleh pengguna akhir (end-user). Beberapa instansi atau perusahaan bahkan telah menggunakan teknologi cloud computing untuk menyimpan filenya agar terhindar dari kendala seperti keterbatasan resource komputer yang menyebabkan tidak maksimalnya kegiatan yang berhubungan dengan perkomputerisasian [1], [2].

Pada saat ini, smartphone sudah menjadi barang yang lumrah digunakan umum. Banyak hal bisa dilakukan dengan smartphone mulai dari browsing, merekam video ataupun memfoto. Semua kegiatan yang direkam dan difoto semua tersimpan pada memori smartphone, sehingga mengurangi ruang pada smartphone dan memperlambat kerjanya. Hal ini sangat mengganggu pengguna smartphone itu sendiri karena harus menghapus beberapa file penting dari ruang penyimpanan bahkan sampai aplikasi yang telah di download, agar smartphone kembali bisa bekerja secara normal dan efektif.

Berdasarkan latar belakang di atas, Dengan memanfaatkan teknologi cloud computing sebagai media penyimpanan file dinilai sangat tepat. Ada banyak keuntungan dari teknologi cloud computing seperti mudahnya akses data di mana saja dan kapan saja selama terhubung pada jaringan internet dan harga yang relatif lebih murah karena tidak memerlukan hardware yang terlalu banyak serta tidak perlunya adanya perawatan rutin / maintenance.

\section{METODE PENELITIAN}

Metodologi penelitian ditunjukkan pada gambar 1 sebagai berikut:

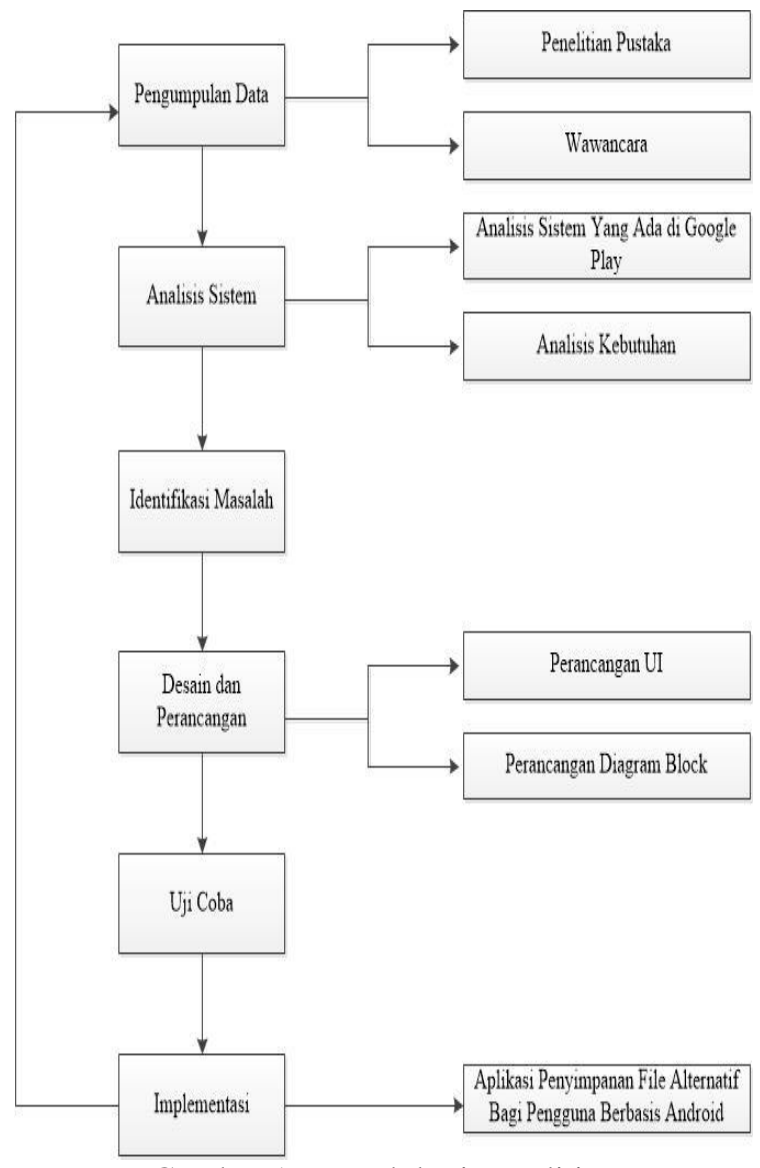

Gambar 1. Metodologi Penelitian 
Metode penelitian yang ingin dirancang tersebut pertama yang dilakukan adalah pengumpulan data berdasarkan kebutuhan aplikasi penyimpanan file dengan melakukan penelitian keperpustakaan, serta melakukan wawancara terhadap pengguna smartphone yang mengalami kendala dalam menyimpan file. Selanjutnya analisis sistem yaitu menganalisis sistem aplikasi yang telah ada pada Google Play. Setelah itu mengidentifikasi masalah yang ada lalu mendesain dan merancang user interface dan diagram block. Sistem akan di uji atau melakukan testing pada aplikasi tersebut untuk mengetahui kelayakan dari sistem yang sudah di rancang. Apabila aplikasi penyimpanan file alternatif bagi pengguna berbasis android tersebut bekerja sesuai dengan kebutuhan maka akan di implementasikan dan digunakan pengguna untuk menyimpan file serta digunakan untuk pengambilan kesimpulan dan pengembangan sistem selanjutnya.

\section{TINJAUAN PUSTAKA \\ 3.1 Firebase Authentication}

Kebanyakan aplikasi pastinya membutuhkan autentikasi pengguna agar memungkinkan aplikasi untuk menyimpan data serta memberikan pengalaman pribadi yang sama pada semua perangkat pengguna. Firebase memberikan layanan backend, SDK yang mudah digunakan serta library siap pakai kepada pengembang aplikasi untuk mengautentikasi pengguna menggunakan kata kunci maupun social media terkenal lainnya seperti Google, Facebook, Twitter dan lainnya [11].

\subsection{Firebase Realtime Database}

Firebase Realtime Database adalah basis data NoSQL yang di-hosting di cloud yang memungkinkan klien menyimpan dan menyinkronkan data di antara pengguna secara realtime. Data yang tersimpan dalam firebase berada dalam bentuk JSON oleh karena itu database ini memiliki optimalisasi dan fungsionalitas yang berbeda dibandingkan dengan basis data relasional [11].

\subsection{Firebase Storage}

Firebase Cloud Storage adalah salah satu layanan pada Firebase yang digunakan untuk menyimpan file ke dalam cloud seperti gambar, audio maupun video. Dengan adanya Firebase Cloud Storage sangat memudahkan pengguna dalam hal mengunggah maupun mengunduh file dari dalam aplikasi. [11].

\subsection{Cloud Storage}

Cloud Storage adalah layanan penyimpanan file di internet pada server virtual yang mana file yang tersimpan dapat dikelola di mana saja oleh pengguna layanan selama penggunanya terhubung ke layanan tersebut melalui jaringan internet [9].

\subsection{Aplikasi Mobile}

Aplikasi mobile adalah aplikasi yang menggunakan perlengkapan seperti PDA, handphone. Aplikasi mobile ini merupakan aplikasi yang dapat memudahkan kita dalam melakukan berbagai aktifitas seperti hiburan, belajar, browsing dan sebagainya[3].

\subsection{Android}

Android adalah sistem operasi mobile yang berkembang saat ini dan berbasis linux kernel yang dirancang untuk perangkat seluler layar sentuh dan komputer tablet. Android disebarkan secara open source[4].

\subsection{Android Studio}

Android studio adalah lingkungan pengembangan terpadu integrated development environment (IDE) berbasis Intellij IDEA yang dirilis oleh google. Sebagai platform pendukung untuk windows, mac OS X dan sistem operasi linux. Versi lama dari pengembangan android yaitu eclipse IDE, dan program plug-in yang disebut dengan ADT (Android Development Tools Plugin) [5].

\subsection{Kotlin}

Kotlin adalah bahasa pemrogaman yang pragmantis artinya bahasa ini mengabungkan object oriented (OO) dan pemrogaman fungsional. bahasa pemrogaman ini dikembangkan oleh JetBrains dan berbasis Java Virtual Machine (JVM). Kotlin juga bersifat interoperabilitas yang artinya bahasa pemrogaman ini dapat digabungkan dengan bahasa pemrogaman java dalam satu project. [10].

\subsection{Java}

Java adalah bahasa orientasi objek yang popular dan merupakan perangkat lunak produksi Sun Microsystems. Java merupakan perangkat lunak pemograman yang multiplatform yang artinya dapat digunakan di berbagai platform seperti desktop, android ataupun Linux. Java memiliki dua program yang berbeda yaitu aplikasi dan applet. Aplikasi merupakan program yang disimpan dan dieksekusi dari komputer lokal sedangkan applet program yang disimpan pada komputer jauh yang dikoneksikan pemakai web browser [10],[12].

\subsection{JDK (Java Development Kit)}

JDK sebuah produk yang dikembangkan oleh Sun Microsystems. JDK merupakan kompiler dan interpreter program java. JDK berisi paket java run time yang komplit. JDK terlebih dahulu di instal supaya dapat mengompilasi aplikasi android [7].

\subsection{Cloud Computing}

Cloud Computing adalah sebuah model komputasi, di mana sumber daya seperti processor / computing power, storage, network, dan software 
berbentuk virtual dan diakses sebagai layanan pada jaringan internet [8].

\subsection{Use Case Diagram}

Use case diagram adalah deskripsi fungsionalitas dari cara kerja sistem dari perspektif pengguna. Use case diagram bekerja dengan tipikal interaksi pengguna dengan sistem yang dilambangkan dengan adanya aktor dan diberikan nilai pada setiap aktor dalam setiap use case [7].

\subsection{Class Diagram}

Class diagram digunakan untuk menggambarkan relasi - relasi antar kelas, objek dan hubungan antar objek yang terdapat dalam sistem. Diagram class terdiri atas nama kelas, atribut kelas dan operasi-operasi dari sebuah kelas juga garis antar kelas yang mendefinisikan setiap hubungan komunikasi antar kelas [3].

\subsection{Activity Diagram}

Activity diagram adalah diagram yang berupa flowchart untuk menggambarkan rangkaian aliran aktivitas dalam sistem ke aliran aktivitas lain serta membantu memahami keseluruhan proses pada sistem. [6].

\section{HASIL DAN PEMBAHASAN}

\subsection{Gambaran Umum Sistem}

Gambaran umum Rancang Bangun Aplikasi Penyimpanan File Alternatif Berbasis Android dapat dilihat pada Gambar 2 berikut :

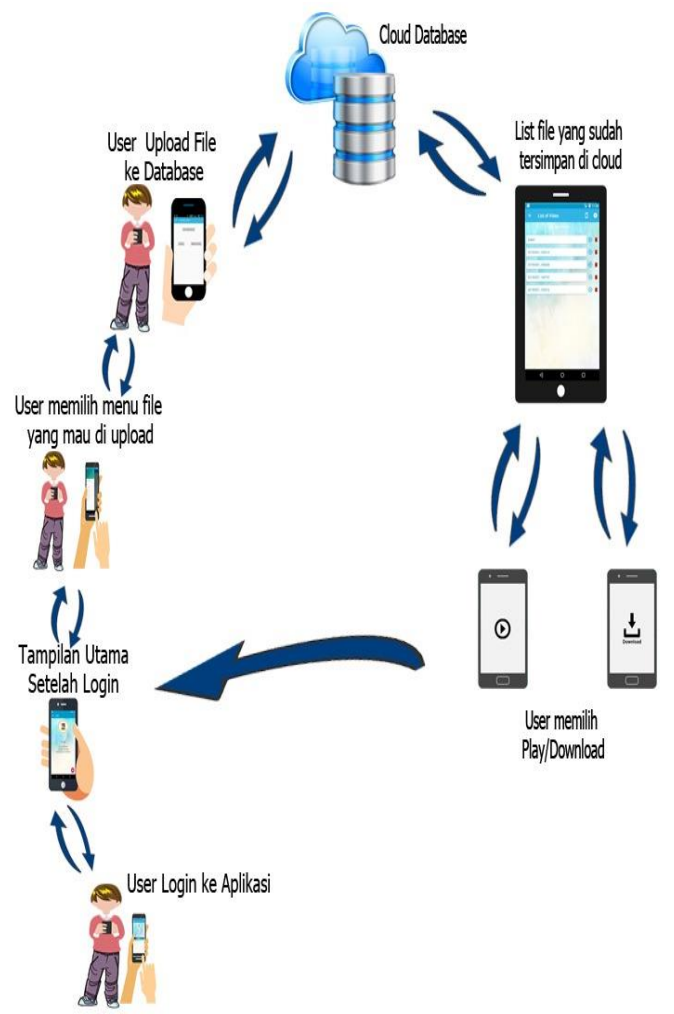

Gambar 2. Gambaran Umum Sistem
Dari gambaran umum sistem diatas pengguna menggunakan android dan login ke aplikasi penyimpanan file, pengguna yang berhasil login akan muncul tampilan utama dari aplikasi tersebut dan memilih menu yang tersedia di samping kiri yang sudah terhubung dengan cloud dan database. Setelah itu, pengguna mengupload file ke cloud database berdasarkan menu yang dipilih. Setelah file tersimpan di cloud akan muncul list file yang telah disimpan. Pengguna bisa mengakses file atau menghapus file tersebut serta mendownload file yang telah disimpan sesuai keinginan pengguna di mana saja dan kapan saja selama ada jaringan internet.

\subsection{Perancangan Use Case Diagram}

Perancangan use case diagram yaitu untuk menggambarkan apa yang dilakukan sistem dan siapa yang berinteraksi dengan sistem. Pemodelan Rancang Bangun Aplikasi Penyimpanan File Alternatif Bagi Pengguna Smartphone Berbasis Android menggunakan Use case diagram. Use case diagram merupakan penjabaran dari Actors dan kebutuhan fungsi use case yang diperlukan di dalam sistem.

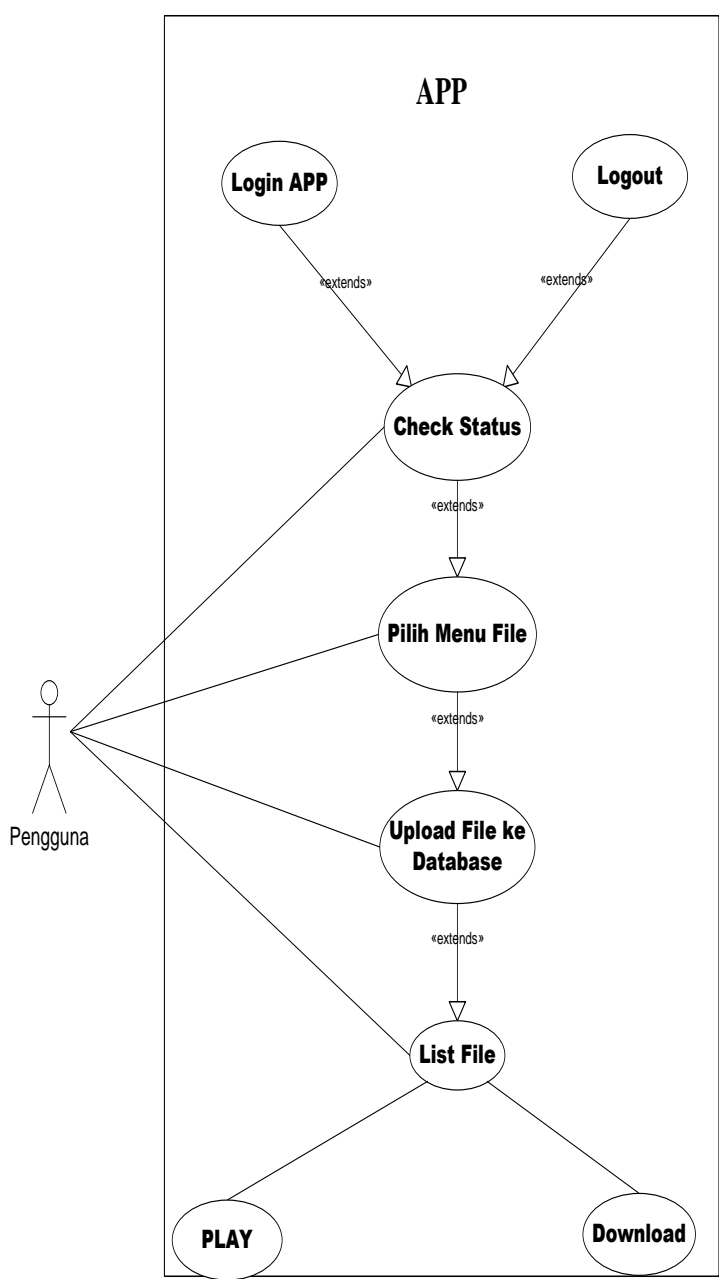

Gambar 3. Rancangan Use Case Diagram 
Jurnal Sistem Informasi dan Ilmu Komputer Prima (JUSIKOM PRIMA)

Vol. 3 No. 1, Agustus 2019

Sistem memiliki satu actors yaitu pengguna yang dapat melakukan pilih menu file yang ingin diupload, proses upload file dan play atau download file.

\subsection{Pemodelan Activity Diagram Aplikasi}

Activity diagram yang memodelkan alur dari sistem. Activity diagram juga bermanfaat untuk menggambarkan interaksi beberapa use case. Dibawah ini merupakan activity diagram dari rancang bangun aplikasi penyimpanan file alternatif bagi pengguna smartphone berbasis android.

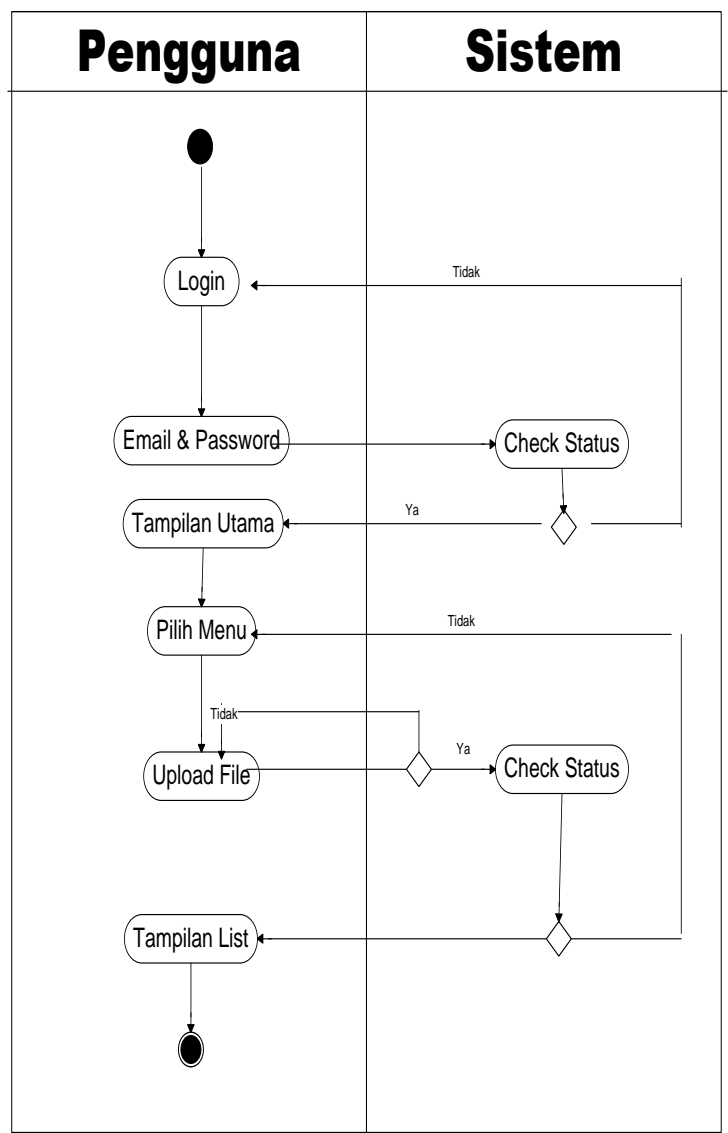

Gambar 4. Activity Diagram Pengguna

\subsection{Tampilan Aplikasi}

Adapun tampilan hasil implementasi Aplikasi penyimpanan file bagi pengguna smartphone berbasis android adalah sebagai berikut: 


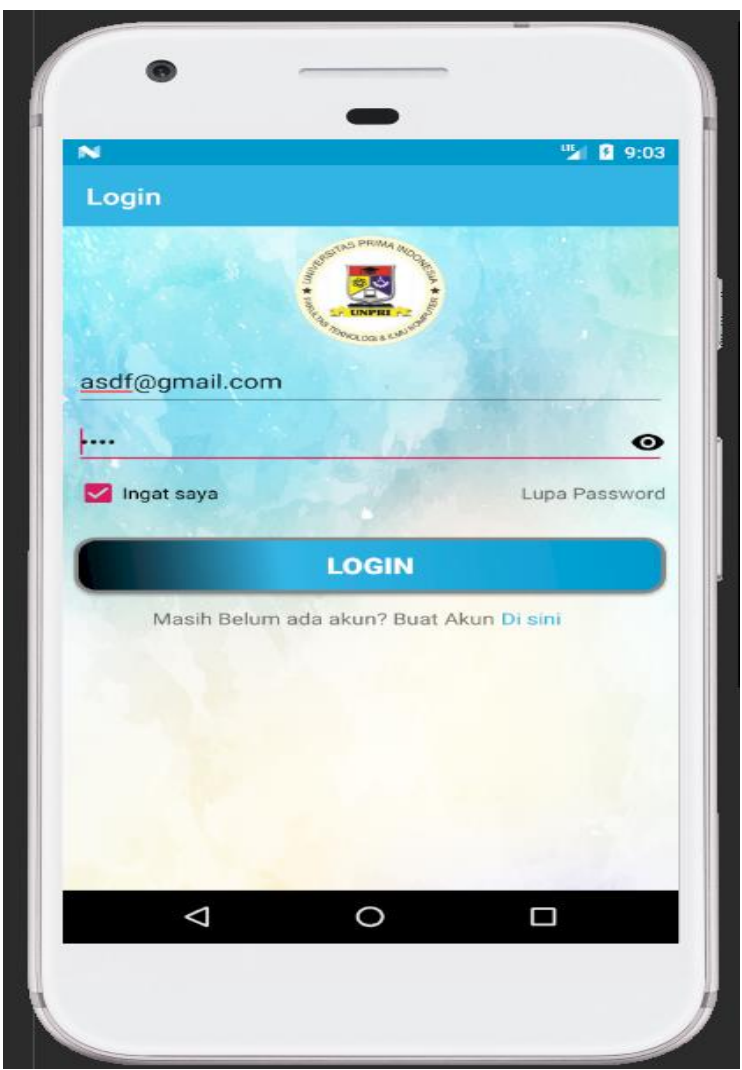

Gambar 6. Login Aplikasi

Setelah pengguna berhasil mendaftar akun, pengguna dapat masuk ke dalam aplikasi menggunakan email dan password. Seperti yang dapat terlihat pada gambar di atas, di samping kolom password juga dapat memperlihatkan password serta apabila pengguna melupakan passwordnya dapat mengreset password.

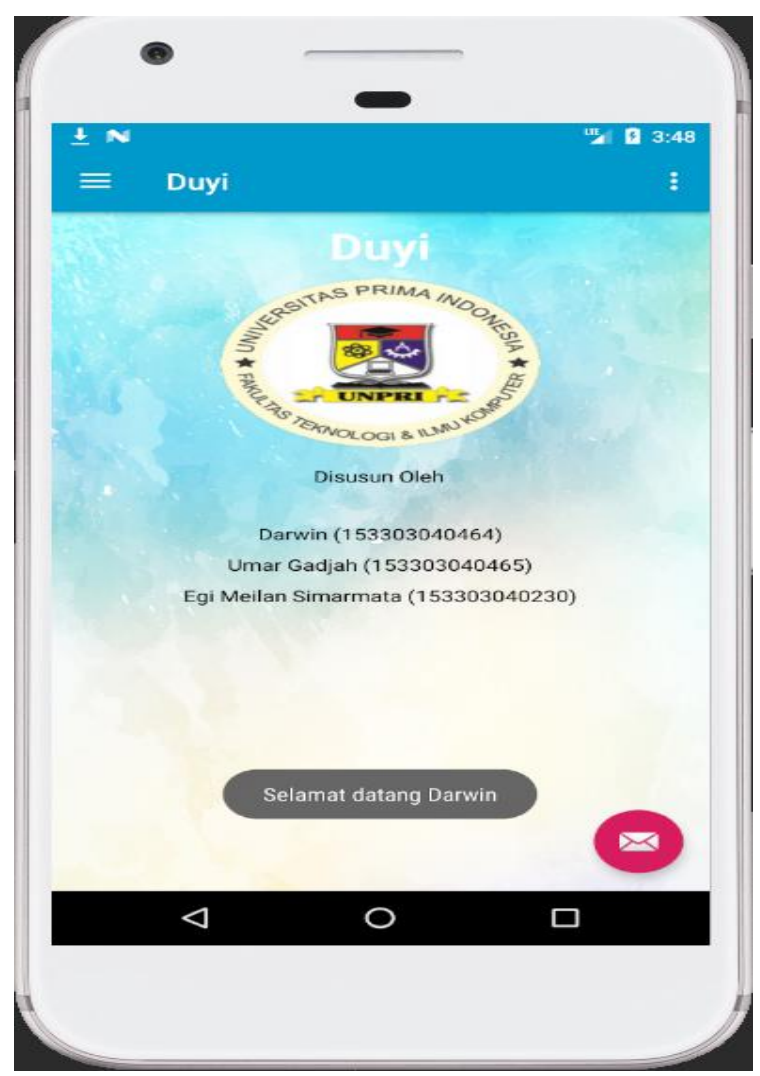

Gambar 7. Halaman Utama Aplikasi

Apabila pengguna berhasil masuk ke dalam aplikasi tersebut maka akan muncul tampilan utama seperti gambar diatas.

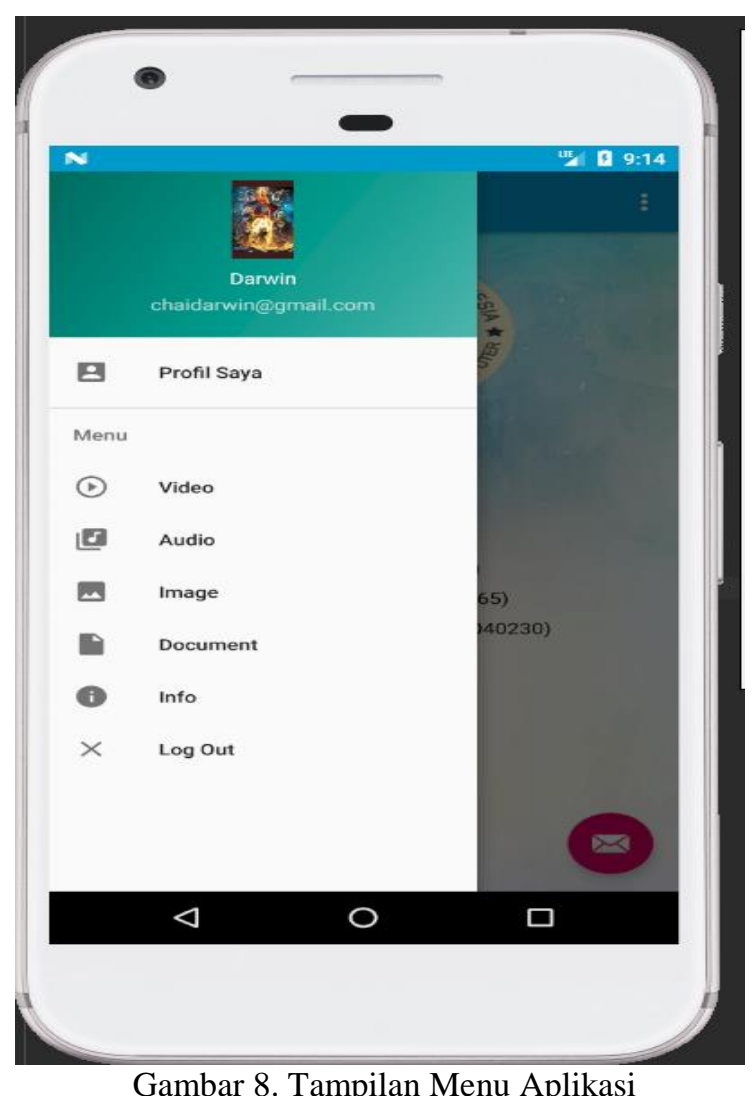

Gambar 8. Tampilan Menu Aplikasi 
Gambar diatas merupakan tampilan menu yang ada di samping aplikasi. Di atas menu juga terdapat informasi pribadi pengguna seperti foto profil, nama serta email pengguna. Selanjutnya pengguna tinggal memilih file yang ingin diupload berdasarkan menu file yang telah tersedia.

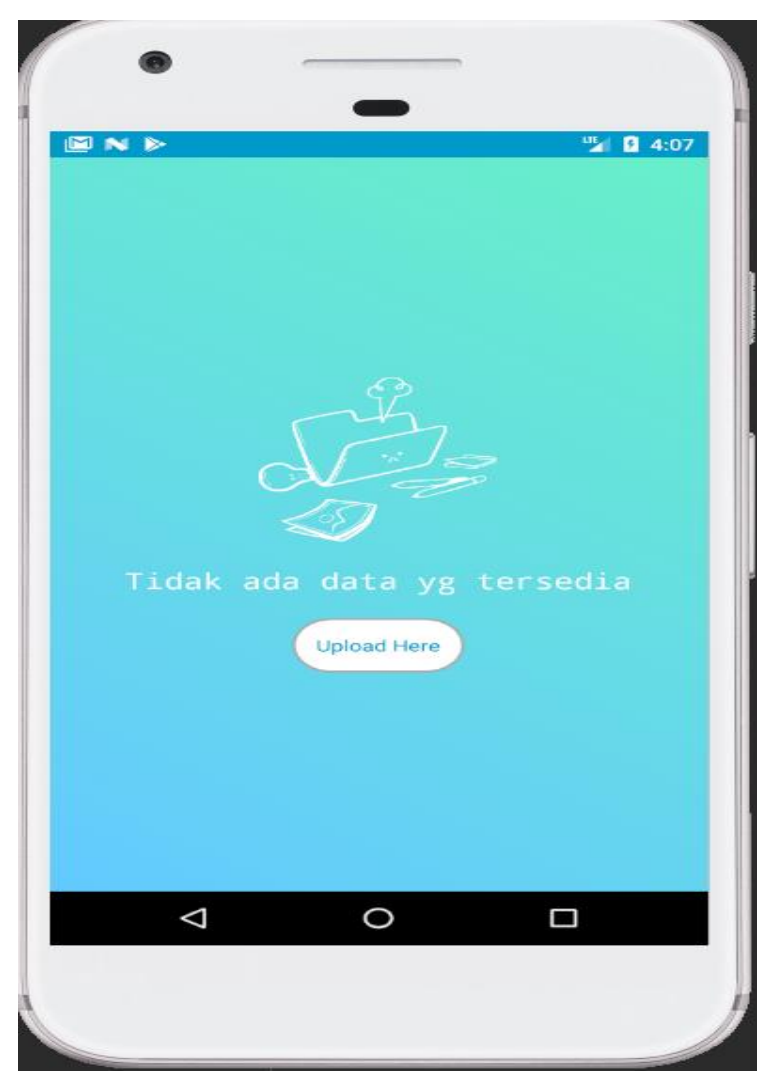

Gambar 9. Tampilan Data Kosong

Gambar diatas merupakan tampilan data kosong apabila pengguna belum mengupload file sebelumnya. Pada tampilan ini, terdapat 1 tombol yang akan mengarahkan pengguna ke tampilan upload file.

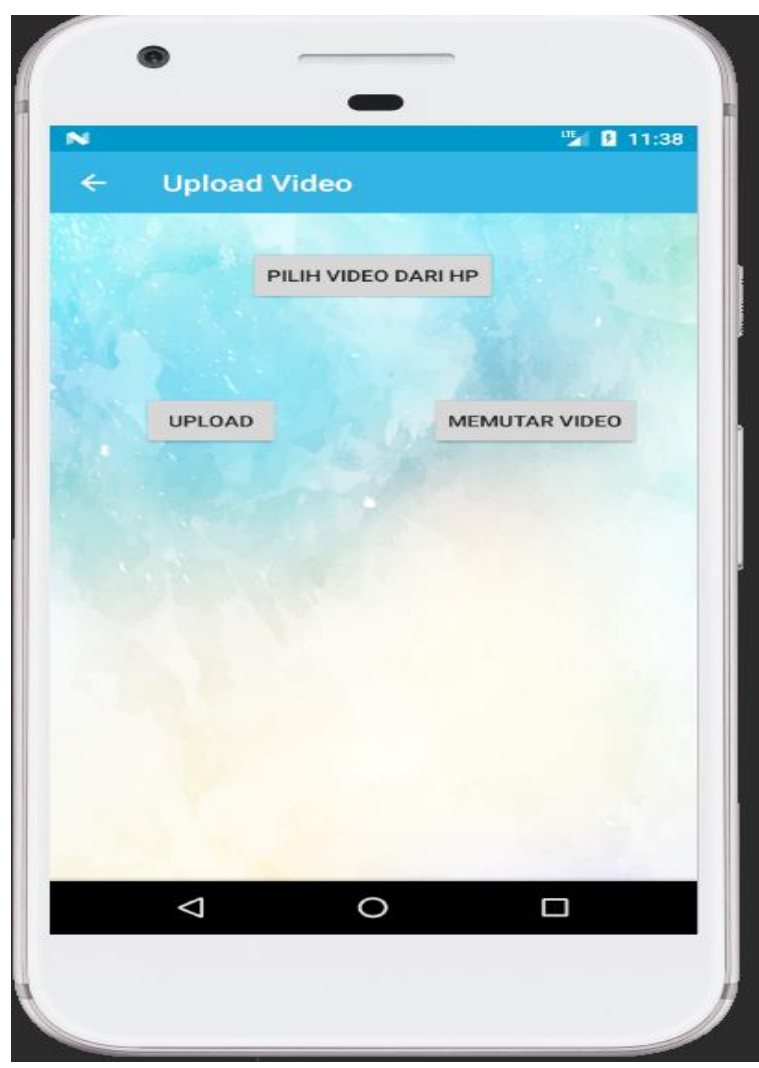

Gambar 10. Tampilan Upload File

Gambar diatas merupakan tampilan upload file video. Pengguna akan memilih file video yang ingin diupload dari hp, lalu klik upload. Pengguna juga dapat memutar video yang sudah dipilih dari hp sebelum diupload dengan mengklik tombol memutar video. 


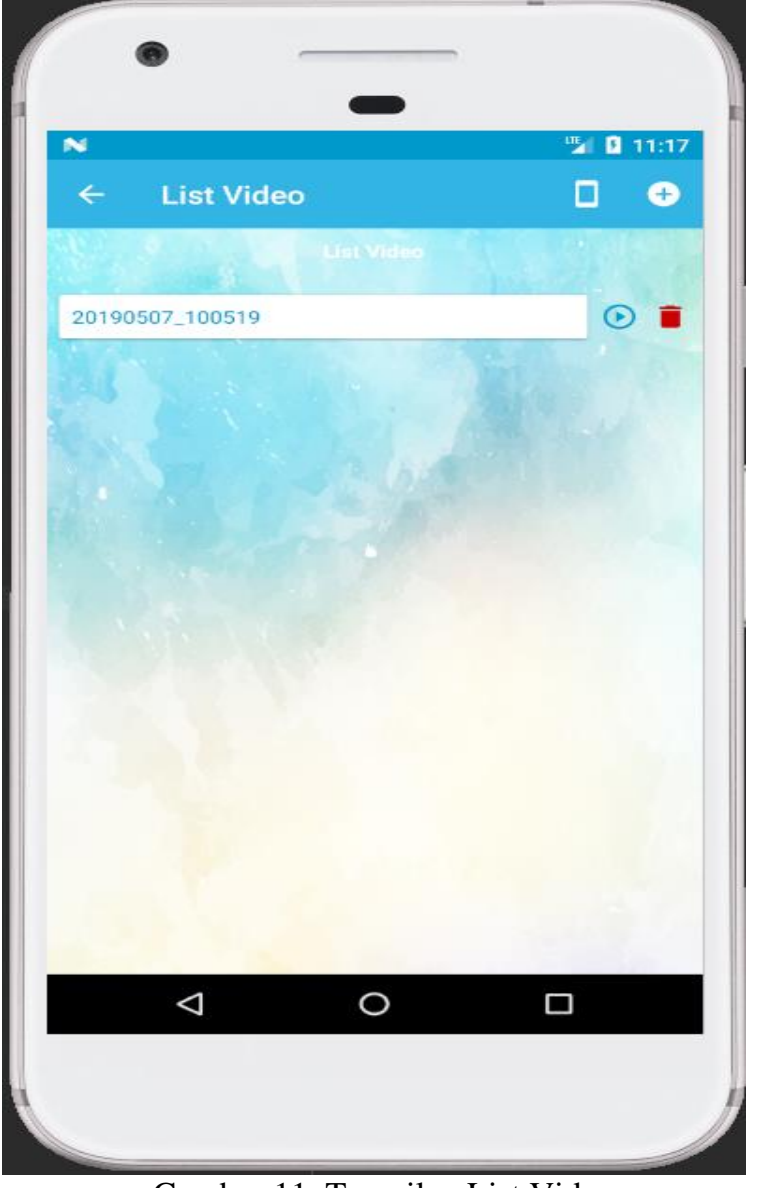

Gambar 11. Tampilan List Video

Apabila pengguna berhasil mengupload file video pada halaman upload video akan muncul tampilan list video yang telah berhasil disimpan ke cloud. File video tersebut dapat dimainkan ataupun dihapus sesuai kehendak pengguna. Di dalam list video juga terdapat dua menu di atas toolbar yaitu merekam video ataupun mengupload file video lainnya dari memori hp pengguna.

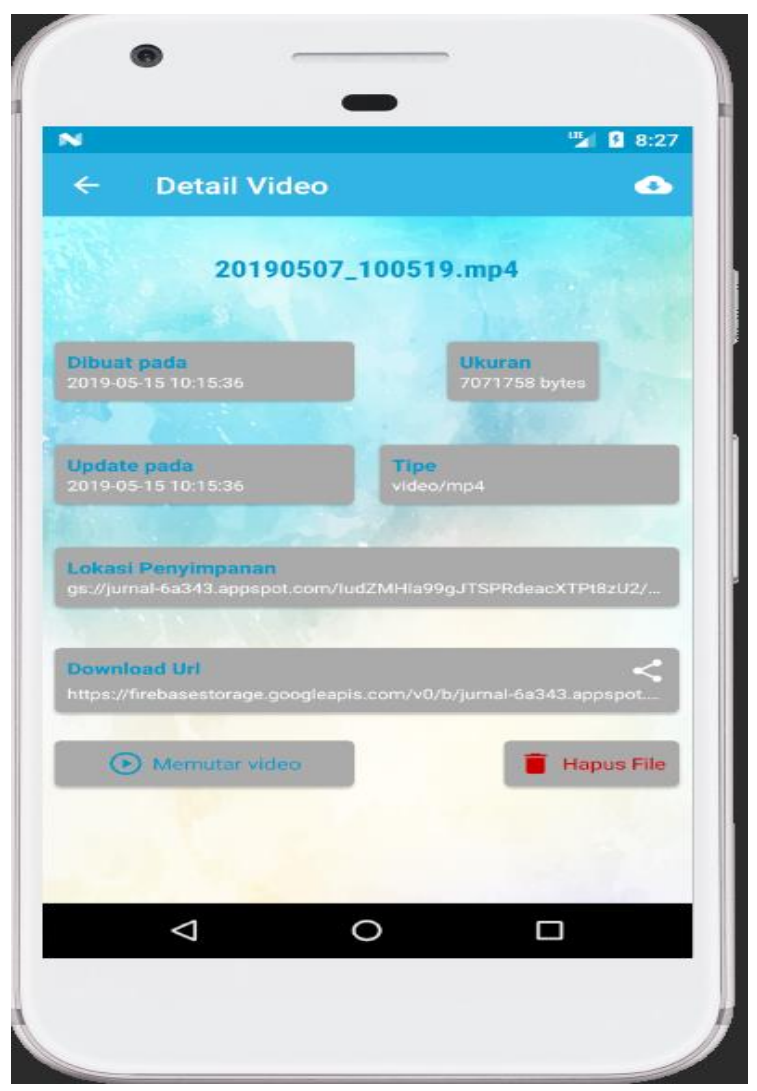

Gambar 12. Tampilan Detail Video

Gambar tersebut merupakan tampilan detail file video yang berisi data data seperti tanggal dibuatnya, tanggal updatenya, ukuran, tipe file, lokasi penyimpanan serta url download yang dapat dibagikan ke media sosial pengguna lainnya. Pada tampilan ini pengguna juga dapat memutar video atau menghapusnya serta terdapat menu untuk mendownload file tersebut pada toolbar di atas.

\subsection{Kelebihan Aplikasi}

Berikut kelebihan dari aplikasi penyimpanan file alternatif berbasis android ini:

1. Aplikasi yang berbasis android sehingga bisa di instal di semua perangkat android.

2. Aplikasi dapat dengan mudah digunakan, hanya perlu menekan tombol untuk mengupload file.

3. Selain untuk menyimpan file, aplikasi ini juga dapat digunakan untuk merekam video, suara dan gambar hanya dalam 1 aplikasi.

4. Aplikasi ini berguna untuk menghemat penggunaan memori hp.

\subsection{Kekurangan Aplikasi}

Aplikasi penyimpanan file berbasis android ini tentunya memiliki kekurangan sebagai berikut :

1. Aplikasi ini mempunyai batasan penyimpanan file.

2. Aplikasi ini membutuhkan os smartphone minimal kitkat (API 19). 
3. Kecepatan akses file bergantung pada kecepatan jaringan internet.

\section{KESIMPULAN}

Dari penelitian yang telah dilakukan rancang bangun aplikasi penyimpanan file alternatif berbasis android ini dibangun dengan menggunakan metode pengembangan aplikasi pemrogaman android native yaitu mengimplementasi bahasa pemrograman kotlin. Aplikasi ini masih banyak kekurangan dibandingkan dengan media penyimpanan lainnya untuk itu dibutuhkan pengembangan lebih lanjut.

\section{DAFTAR PUSTAKA}

[1] Jamaluddin. 2015. Pemanfaatan Fasilitas Cloud Computing Untuk Pembuatan Dokumen Dan Presentasi.

[2] Euis, Heryana Nono. 2018. Analisis Pemanfaatan Cloud Computing Berbasis Software as a Service sebagai Media Penyimpanan Tugas Praktikum.

[3] Kosidin, Farizah Nur Resha. 2016. Pemodelan Aplikasi Mobile Reminder Berbasis Android. Seminar Nasional Teknologi informasi dan Komunikasi.

[4] Supardi yuniar. 2017. Koleksi Program Tugas Akhir dan Skripsi dengan Android. Jakarta: PT.Elex Media komputindo.

[5] Weng Sheng- Ting, Hsu Hui- Meng, and Yang Ching- Der. 2017. Developing an Online Examination APP System. International Journal of Information and Education Technology.7(8).

[6] Priati, Rerung Rante Rintho. 2017. Sistem Ujian Saringan Masuk Perguruan Tinggi Berbasis Android. Seminar Nasional Teknologi Informasi dan Komunikasi.

[7] Kusniyati Harni, Sitanggang.P.S.N. 2016. Aplikasi Edukasi Toba Samosir Berbasis Android. Jurnal Teknik Informatika.9(1): 9- 18.

[8] W. Ono Purbo. 2012. Membuat Sendiri Cloud Computing Server Menggunakan Open Sourcem.

[9] Kholil Moch, Mu'min Syahri. 2018. Pengembangan Private Cloud Storage sebagai Sentralisasi Data Universitas Nahdlatul Ulama Sidoarjo Berbasis Open Source Owncloud.

[10] Sibarani Sumanda Niko, Munawar Ghifari, Wisnuadhi Bambang. 2018. Analisis Performa Aplikasi Android Pada Bahasa Pemrograman Java dan Kotlin.

[11] Ilhami Mirza. 2017. Pengenalan Google Firebase Untuk Hybrid Mobile Apps Berbasis Cordova.

[12] Lengkong Nugraha Hendra, sinsuw A.E Alicia, Lumenta S.M Arie. 2015. Perancangan Penunjuk Rute Pada Kendaraan Pribadi Menggunakan Aplikasi Mobile GIS Berbasis Android Yang Terintegrasi Pada Google Maps. E-journal Teknik Elektro dan Komputer.

[13] M. Diarmansyah Batubara and E. Indra, "Perencanaan dan Pembuatan Aplikasi
Pengerjaan Ujian Nasional Tingkat SMP Berbasis Android," Query: Jurnal. Sistem. Informasi., pp. 2579-5341, 2018.

[14] A. L. Sitanggang, M. Hati Loi, and E. Indra, "Rancang Bangun Aplikasi Sistem Ujian Saringan Masuk Sma Berbasis Android (Studi Kasus SMA Amir Hamzah Medan)," Jurnal Sistem Informasi dan Ilmu Komputer Prima (JUSIKOM PRIMA), vol. 2, no. 2, 2019.

[15] E. Indra and M. Nababan, "Aplikasi Pendataan Lokasi Bengkel Resmi Sepeda Motor Di Kota Medan Berbasis Android Menggunakan Algoritma Floyd Warshall," Jurnal Sistem Informasi dan Ilmu Komputer Prima (JUSIKOM PRIMA), vol. 1, no. 1, 2017. 